\title{
Effects of Listener's Histories on Following Rules that are Discrepant to Contingencies
}

\author{
Fernanda Monteiro Lima \\ University of the Amazon, Belém, PA, Brazil \\ Luiz Carlos de Albuquerque ${ }^{1}$ \\ Carla Cristina Paiva Paracampo \\ Federal University of Pará, Belém, PA, Brazil
}

\begin{abstract}
Testing proposition by aiming on the listener's history critical characteristics that may meddle on the discrepant-rule following, eight college students were exposed to a matching to sample procedure. The task was to point to the three comparison stimuli in a sequence. In Phase 1 no sequence was instructed or reinforced. Phase 2 begun with the rule corresponding to the contingencies. Contingencies effective in Phase 2 were shifted without warning in Phase 3. Contingencies in Phase 3 were kept unchanged in Phase 4, which started with the presentation of a discrepant rule. Six out of eight participants showed an independent behavior and two out of eight showed a dependent behavior from its immediate consequences in Phase 3. From those six out of eight participants showing an independent behavior, four managed to follow the discrepant-rule in Phase 4. And from the latter two out of eight showing a dependent behavior, all of them abandoned the discrepant-rule following in Phase 4. It is suggested that the behavior's dependence and independence to its immediate consequences, before the discrepant-rule presentation, are critical variables of the listener's history that may be used to foresee maintenance, or not, from the subsequent discrepant-rule following.
\end{abstract}

Keywords: Rule-governed behavior, contingency shaped behavior, justifications, immediate consequences, insensitivity to contingencies.

\section{Efeitos de Histórias do Ouvinte sobre o Seguimento de Regras Discrepantes das Contingências}

\section{Resumo}

Objetivando testar proposição sobre as características críticas da história do ouvinte que podem interferir no seguir regra discrepante, oito universitários foram expostos a um procedimento de escolha segundo o modelo. A tarefa era apontar para os três estímulos de comparação em sequência. Na Fase 1, nenhuma sequência era instruída ou reforçada. A Fase 2 era iniciada com a regra correspondente. As contingências da Fase 2 eram alteradas, sem sinalização, na Fase 3, e as contingências da Fase 3 eram mantidas inalteradas na Fase 4, iniciada com a

\footnotetext{
Mailing address: Av. Gov. José Malcher, 163/Apto. 06 - B, Nazaré, Belém, PA, Brazil 66035-100. E-mail: lcalbu@ufpa.br, cparacampo@gmail.com and nandalima@hotmail.com

Work based on data from the master's thesis of the first author (Graduate Program in Behavior Theory and Research of the Federal University of Pará) and performed with the aid of National Council for Scientific and Technological Development (CNPq), in the form of a research productivity grant to the second and third authors.
} 
regra discrepante. Dos oito participantes, seis apresentaram um comportamento independente e dois apresentaram um comportamento dependente de suas consequências imediatas na Fase 3. Dos seis participantes que apresentaram um comportamento independente das consequências imediatas na Fase 3, quatro seguiram a regra discrepante na Fase 4. E dos dois participantes que apresentaram um comportamento dependente das consequências imediatas na Fase 3, todos abandonaram o seguimento da regra discrepante na Fase 4. Sugere-se que a dependência e a independência do comportamento às suas consequências imediatas, antes da apresentação da regra discrepante, são variáveis críticas da história do ouvinte que podem ser utilizadas para se prever a manutenção, ou não, do seguimento subsequente de regra discrepante.

Palavras-chave: Comportamento governado por regras, comportamento modelado por contingências, justificativas, consequências imediatas, insensibilidade a contingências.

\section{Efectos de Historias del Oyente acerca del Seguimiento de las Reglas Discrepantes de las Contingencias}

\section{Resumen}

Con objetivo de probar proposición acerca de variables que pueden interferir acerca del seguimiento de regla, ocho estudiantes universitarios fueron expuestos a un procedimiento de elección de acuerdo con el modelo. La tarea era señalar a los tres estímulos de comparación en secuencia. En Fase 1, ninguna secuencia era enseñada o reforzada. Fase 2 comenzaba con la regla correspondiente a las contingencias programadas. Contingencias de Fase 2 eran cambiadas, sin señalización, en Fase 3, y contingencias de Fase 3 eran conservadas en Fase 4, comenzada con la regla discrepante de las contingencias. De los ocho participantes, seis presentaron un comportamiento independiente y dos presentaron un comportamiento dependiente de sus consecuencias inmediatas en Fase 3. De los seis participantes que presentaron un comportamiento independiente de las consecuencias inmediatas en Fase 3, cuatro seguirán la regla discrepante en Fase 4. Y de los dos participantes que presentaron un comportamiento dependiente de las consecuencias inmediatas en Fase 3, todos abandonaran el seguimiento de regla discrepante en Fase 4. Se sugiere que dependencia y independencia del comportamiento a sus consecuencias inmediatas son variables críticas de la historia del oyente que pueden ser usadas para predicción del mantenimiento, o no, del seguimiento subsiguiente de regla.

Palabras clave: Comportamiento gobernado por reglas, comportamiento modelado por contingencias, justificaciones, consecuencias inmediatas, insensibilidad a contingencias.

Rules are verbal antecedent stimuli that can describe behavior and its control variables, establish the topography of new behaviors, and alter stimuli functions, independently of the immediate consequences produced by the behavior and the spatiotemporal contiguity between stimulusbehavior and stimulus-stimulus (Albuquerque, Paracampo, Matsuo, \& Mescouto, 2013). This definition differs from the three major previous rule definitions recorded in the literature [i.e., it differs from the definitions that indicate that rules are stimuli: specifiers of contingencies that act as discriminative stimuli (Skinner, 1969), verbal antecedents (Zettle \& Hayes, 1982), and changers of other stimuli's functions (Schlinger \& Blakely, 1987)], mainly because it emphasizes that rules may exercise their functions independently of the immediate consequences produced by the behavior and the spatiotemporal contiguity between stimulus-behavior and stimulusstimulus (Albuquerque \& Paracampo, in press).

Rules exercise their functions partly due to current environmental variables and historical variables. The main current environmental variables that can interfere with control by rules are the types of immediate consequences produced 
by following and not following rules (positive reinforcement, negative reinforcement, extinction, and punishment) and the types of justifications for following and not following rules (Albuquerque \& Paracampo, in press).

Immediate consequences are events that are immediately produced (contacted) by behavior after its emission. Justifications ${ }^{2}$ are rule's constituent stimuli that can alter the function of stimuli and determine the topography of behavior and its likelihood to occur and be maintained. Rules may be without justifications (for example, the rule: "Don't go to Y; stay here at X") or with justifications (for example, "Don't go to Y; stay here at X. You won't have support in $\mathrm{Y}$, whereas here at $\mathrm{X}$, you'll have

Four aspects must be clarified: (a) future events reported in the justifications are verbal background stimuli constituents of the rule and can exercise control over the behavior at the time the rule is presented, when the listener comes into contact with the rule (Albuquerque, Silva, \& Paracampo, 2014; Matsuo, Albuquerque, \& Paracampo, 2014). (b) The reported future event itself does not exercise control over the behavior because the event is not produced by the behavior at the time the rule is presented. When the reported event is produced by the behavior, it is not produced as a future event but rather as an immediate consequence of the behavior, which is how it can exercise control. Thus, the rule functions as a current substitute for the future event reported by it (Albuquerque et al., 2014; Matsuo et al., 2014). (c) A behavior and a future event may be part of a contingency of reinforcement. However, when this relationship is described for a listener and the behavior specified by this rule occurs, before coming into contact with the reported event, such behavior must be considered to be controlled by the rule (Paracampo, Albuquerque, Mescouto, \& Farias, 2013). (d) The future event reported by the justification is not always able to be produced (the case of justifications that state that rule following will produce, for example, the blessing of God and a heaven or a hell after death) or is clearly produced (the case of justifications that state that rule following will produce, for example, approval, admiration, happiness, security, and health) by the behavior specified by the rule. In such cases, the approval is indicated by justifications and not by immediate consequences (Albuquerque \& Paracampo, in press; Albuquerque et al., 2014; Matsuo et al., 2014). everything you need and also have your family to help you"). In this example, the differential justifications not to go to $\mathrm{Y}$ and to stay at $\mathrm{X}$ would change the probability that the listener will stay at $\mathrm{X}$. Therefore, in general, rules can evoke and determine the topography of behavior and alter the function of stimuli. However, unlike when rules have no reported justifications, when rules have reported justifications, such justifications may select and maintain the behavior (Albuquerque \& Paracampo, in press).

The main types of justifications are verbal antecedent statements regarding:

1. The eventual consequences of following or not following rules; observed in statements that may indicate whether the consequences are adverse or reinforcing, of great or small magnitude, near or future, whether they can be contacted or not;

2 . The eventual approval or disapproval for following or not following the rule; observed in statements that can indicate whether the speaker or other individuals approve, or not, following the rule;

3. The listener's trust in the speaker; expressed in statements such as "I think", "I have experience", "I'm certain", and "Trust me", which can indicate whether the reported consequences will actually be produced, or not, by following the rule;

4. The form of the rule; observed in statements that can indicate whether the rule has the form of a promise, order, threat, agreement, speech, propaganda, documentary, or law, among others; and

5. 5. What to observe: statements that may indicate examples of behaviors to follow and examples of behaviors not to follow (Albuquerque \& Paracampo, 2017a; Albuquerque \& Paracampo, in press; Albuquerque et al., 2013, Albuquerque et al., 2014; Paracampo et al., 2013; Matsuo et al., 2014).

For example, a speaker may present the rule "Do not take college major Y; take major X" and add the following justifications: "You will see that you will get a good job with a good salary" (Type 1 justification); "Your father will be very proud of you, and you will be able to help others" 
(Type 2 justification); “I'm sure you'll get a good job, trust me" (Type 3 justification); "I'm asking you" (Type 4 justification); "So-and-so took this college major; he is already employed, and look how well he's doing. He was even able to buy an apartment" (Type 5 justification). What is common in all of these examples is that the justifications are verbal antecedent stimuli that can alter functions of stimuli and interfere in the selection and maintenance of rule following and not following (Albuquerque \& Paracampo, 2017a; Albuquerque \& Paracampo, in press).

When the behavior is controlled by rules, the behavior topography and its likelihood to occur and be maintained, in addition to the functions of the stimuli, are determined by justifications. When the behavior is controlled by reinforcement contingencies, the immediate consequences are those that exercise these functions. Thus, the effects of rules with justifications are similar to the effects of contingencies of reinforcement, either verbal or non-verbal. Unlike such contingencies, rules with justifications are defined by being verbal antecedents stimuli that can perform the function of establishing and maintaining behavior, independently of the immediate consequences produced by the behavior and the spatiotemporal contiguity between stimulus-behavior and stimulus-stimulus ${ }^{3}$ (Albuquerque \& Paracampo, in press).

The maintenance of the behavior of rule following and not following may depend on three

This defining property of rules with justifications is also what differentiates such mand and autoclitic rules. By definition, rules with justifications exercise such functions as environmental variables (i.e., as independent variables). Differently, mands and autoclitics, by definition, are behaviors (i.e., they are dependent variables). As behavior, the mand's effect on the listener is to produce the specified reinforcement, and the autoclitic's effect on the listener is to produce the appropriate reinforcement. Therefore, in both cases, the action of the listener who follows the presentation of a mand or an autoclitic is to function as an audience, to reinforce (or punish), and/or to mediate the reinforcement of the speaker's behavior, be it mand or autoclitic (Albuquerque \& Paracampo, in press). main listener histories, which differ in regard the sources of behavioral control specified by the rule. In the history of control by immediate differential consequences, the behavior specified by the rule is placed under the control of the rule by its immediate differential consequences and not by justifications. In the history of control by differential justifications, the behavior specified by the rule is placed under the control of the rule by differential justifications and not by immediate consequences. In the control history by interaction between justifications and immediate differential consequences, for rule following and not following, the behavior specified by the rule is placed under the control of the rule by these combined variables (Albuquerque \& Paracampo, 2017a; Albuquerque \& Paracampo, in press).

In the present study, we seek to identify the critical features that a listener's history must present to interfere with maintaining subsequent discrepant rule following. Some studies have sought to identify such critical features (Albuquerque, Mescouto, \& Paracampo, 2011; Albuquerque, Paracampo, \& Allan, in press; Albuquerque, Reis, \& Paracampo, 2006; Albuquerque, Reis, \& Paracampo, 2008; Albuquerque \& Silva, 2006; Albuquerque et al., 2014). Here, two aspects must be highlighted. First, in all procedures described below, the correspondent and discrepant rules contain the Type 2 justification (statements about the eventual approval or disapproval for following or not following the rule; i.e., "When I show you these objects, you must do the following:", which indicates that the experimenter approved following the rule, and the Type 1 justification; statements about the eventual consequences of following or not following rules; i.e., "By doing this, you can earn points, which will be shown at the counter in front of you", which indicates that the participant would earn points that would be exchangeable for money if she/ he followed the rule). The rule is called minimal ("Point with your finger in sequence to each of the three objects of comparison") because it does not specify which sequence should be used and does not have clear justifications. The rule is named correspondent when the immediate consequence produced by the behavior specified by 
it corresponds to the Type 1 justification component of the rule (i.e., in this case, when rule following produces a point - exchanged for cash at the end of the study). The rule is called discrepant when the immediate consequence produced by the behavior specified by it does not correspond to the Type 1 justification component of the rule (i.e., when rule following does not produce points). Second, a criterion to evaluate the behavior's dependence on or independence of the immediate consequences produced by it is to check whether the behavior occurs under the control (i.e., if it is dependent) of its immediate consequences or whether it occurs not under the control (i.e., if it is independent) of such consequences (Albuquerque \& Paracampo, 2017b; Albuquerque \& Paracampo, in press). This evaluation can be performed in at least two ways: (a) while maintaining unchanged the contingencies of reinforcement planned in the experiment and manipulating the rules (the alternative procedure, such as those used in the studies by Albuquerque, de Souza, Matos, \& Paracampo, 2003; Albuquerque et al., 2006, 2008; Martinez \& Tomayo, 2005); and, (b) while maintaining the rules unchanged and manipulating the contingencies of reinforcement planned in the experiment (the traditional procedure, such as those used in the studies by Galizio, 1979; Hayes, Brownstein, Zettle, Rosenfarb, \& Korn, 1986; Martinez \& Tomayo, 2005; Paracampo \& Albuquerque, 2004; Perez, Reis, \& de Souza, 2010; Shimoff, Catania, \& Matthews, 1981; Torgrud $\&$ Holborn, 1990). Thus, the term independence describes a behavior that is not under the control of its immediate consequences, and the term dependence describes a behavior that is under the control of its immediate consequences in a given situation (Albuquerque et al., 2003; Albuquerque \& Paracampo, 2017b; Albuquerque \& Paracampo, in press).

For example, using a procedure that combines the characteristics of traditional and alternative procedures, Albuquerque et al. (2014) compare the effects of two specific listener's histories on the subsequent discrepant rule following. To that end, 10 university students are exposed to a matching-to-sample procedure ac- cording to the model, adapted from that developed by Albuquerque (1991). The participants are divided into two groups, with five participants each and exposed to four phases. Phase 1 consists of 10 baseline trials in which no sequence is reinforced or instructed. In Phase 2, the correct sequence is reinforced in a continuous reinforcement schedule (CRF), and after 10 points are earned, it is reinforced in a fixed ratio of 2 schedule (FR 2) until 10 points are earned, at which point this phase is terminated. In Phases 3 and 4, the correct sequence is reinforced in CRF. These two last phases are terminated according to one of the following criteria, whichever occurs first: after earning 10 points or after 30 trials. The groups differ in regard to how to establish the correct sequence (color, thickness, shape - CTS) in Phase 2 [by differential reinforcement in Group DR and correspondent rule (instruction) in Group IN]. In Phase 3, the contingencies are changed, without warning, and the new correct sequence is TSC. Finally, in Phase 4, the contingencies are kept unchanged; that is, emitting the TSC sequence still produces points, and the discrepant rule (which specifies that, if the participant pointed in the SCT sequence, then she/he would earn points) is introduced.

In Group $\mathrm{RD}$, of the four participants who achieve the performance criterion for termination of Phase 2 and, for this reason, are exposed to Phases 3 and 4, three of them (P12, P13 and $\mathrm{P} 14)$ present a behavior that is dependent on the immediate consequences programmed in Phase 3. Of these three, one (P12) follows and two (P13 and P14) no longer follow the discrepant rule in Phase 4 and begin to display the behavior that is dependent on its immediate consequences. The only participant (P11) who answers independently of the immediate consequences programmed in Phase 3 follows the discrepant rule in Phase 4. In Group IN, four of the five participants (P22, P23, P24 and P25) continue rule following, independently of the immediate consequences programmed in Phase 3 (i.e., they display a behavior that is insensitive ${ }^{4}$ to the change

4 The term insensitivity is proposed by Shimoff et al. (1981) to describe rule following that does 
in the programmed contingencies) and follow the discrepant rule in Phase 4 . The only participant (P21) who stops rule following and displays a behavior that is dependent on the immediate consequences programmed in Phase 3 (i.e., the participant who displays a behavior sensitive to the change in the programmed contingencies) abandons discrepant rule following in Phase 4.

The results of P13 and P14 support the proposition by Torgrud and Holborn (1990) that it is unlikely that rules exert control over behavior when the reinforcement contingencies show discriminative control before the introduction of the rule. They also support the proposition that discrepant rule following is unlikely to be maintained when, before the introduction of this rule, differential reinforcement establishes a behavior that is alternative to that specified by the discrepant rule and this behavior is maintained in a continuous reinforcement schedule (Albuquerque et al., 2006). However, these propositions are not sufficient to explain all of the results of the study under review.

According to Albuquerque and Paracampo (2017b), Albuquerque et al. (in press) and Albuquerque et al. (2014), the differences between the Phase 3 behaviors may be partly due to the differences between the listener's histories in Phase 2. For example, in the history of Phase 2 of Group IN, the Type 2 justification, when indicating that the experimenter approves rule following, is a variable that is favorable to maintaining the behavior, independently of its immediate consequences, including in Phase 3. In Group $\mathrm{RD}$, because there is no justification, the differential immediate consequences are variables that indicate the correct sequence (the sequence that produces reinforcement) and the incorrect sequences (those that produce extinction). Thus, such consequences are variables that are favorable to maintaining a behavior that is dependent on its immediate consequences, including in Phase 3. The differences between the

not change when the programmed contingencies of reinforcement change. However, there are controversies concerning the adequacy of using this term (see Albuquerque \& Paracampo, 2017b). performances in Phase 4, in turn, may be partly due to the differences between the listener's histories in Phase 3. Evidence of this explanation is that discrepant rule following is more likely to be maintained when the behavior presented before the listener's contact with the discrepant rule (Phase 3) is maintained, independently of its immediate consequences. Moreover, discrepant rule following is more likely to fail to occur when this behavior depends on its immediate consequences. Therefore, the results of eight of the nine (89\%) participants exposed to Phases 2 and 3 replicate the results from previous studies (Albuquerque et al., 2013; Albuquerque \& Silva, 2006; also, see Albuquerque \& Paracampo, $2017 \mathrm{~b}$ ) and agree with this proposition (Albuquerque \& Paracampo, 2017b; Albuquerque et al., in press; Albuquerque et al., 2014).

The generality of this proposition can be tested in studies that investigate the effects of extended histories of behavior reinforcement established by the correspondent rule on the subsequent discrepant rule following. Such investigations are important, mainly because they can help clarify the role of historical variables that interfere with discrepant rule following. For example, Albuquerque et al. (2008, Experiment 2) investigate the effects of a prolonged history of trials (terminated after 320 programmed reinforcements) by the interaction between immediate consequences and justifications for correspondent rule following on the subsequent behavior of discrepant rule following. To that end, four university students are exposed to a matching-to-sample procedure according to the model adapted from that developed by Albuquerque (1991). The correct sequence is reinforced in a continuous reinforcement schedule (CRF). The participants are exposed to the minimal, correspondent, and discrepant rules at the beginning of Phases 1, 2, and 3, respectively. Phase 1 (baseline) is terminated after 10 trials, Phase 2 after earning 320 points, and Phase 3 after 240 trials or earning 80 points, whichever occurs first. The four participants follow the correspondent rule in Phase 2. In Phase 3, all participants stop following the discrepant rule and begin to display the alternative behavior to that 
specified by the rule, previously established by the correspondent rule in Phase 2.

Albuquerque et al. (in press) perform a systematic replication of the study by Albuquerque et al. (2008, Experiment 2) with four new university students. Unlike in Albuquerque et al. (2008, Experiment 2), in Albuquerque et al. (in press), the correct sequence is reinforced in a fixed ratio of 4 schedule (FR 4 ) and the dependence of the rule following behavior to the immediate consequences was tested at the beginning of Phase 2. All four participants follow the correspondent rule in Phase 2 and follow the discrepant rule during Phase 3, in more than $98 \%$ of trials in each phase.

It is not clear which variables may have contributed to determining the differences between the results of the studies by Albuquerque et al. (2008, Experiment 2 - long CRF) and Albuquerque et al. (in press - prolonged FR 4). One possibility is that, in the study by Albuquerque et al. (in press - prolonged FR 4), the participants follow the discrepant rule in Phase 3 because the behavior of following similar rules was reinforced in the past (Skinner, 1974). However, this history in Phase 2 is not sufficient to maintain discrepant rule following in Phase 3 in the study by Albuquerque et al. (2008, Experiment 2 - prolonged CRF). Therefore, another possibility is that discrepant rule following is abandoned in the study by Albuquerque et al. (2008, Experiment 2 - prolonged CRF) and maintained in the study by Albuquerque et al. (in press - prolonged FR 4) due to differences between the reinforcement schedules used in these two studies (Newman, Buffington, \& Hemmes, 1995). One problem with this explanation is that there is experimental evidence that shows that discrepant rule following can be maintained even when, before being exposed to the discrepant rule, the participant has a short history of continuous reinforcement (terminated after 80 reinforcements) of the behavior established by the correspondent rule (Albuquerque et al., 2006, Experiment 1 - short CRF). The combined results of the studies by Albuquerque et al. (2006, Experiment 1 - short CRF) and Albuquerque et al. (2008, Experiment 2 - prolonged CRF) indicate that the extent of the listener's history in Phase 2 of the study by Albuquerque et al. (2008, Experiment 2 - prolonged CRF) may have contributed to preventing maintaining the subsequent discrepant rule following in Phase 3 of this study. However, the combined results of the studies by Albuquerque et al. (2008, Experiment 2 - prolonged CRF) and Albuquerque et al. (in press - prolonged FR 4) suggest that the extent of the history itself is a variable that is not sufficient to prevent subsequent discrepant rule following.

Another possibility is to assume that discrepant rule following no longer occurs in Phase 3 of the study by Albuquerque et al. (2008, Experiment 2), possibly because the behavior detected prior to the presentation of the discrepant rule is maintained, depending on its immediate consequences. One piece of evidence is that, in this study, the behavior is only maintained in Phases 2 and 3 when it produces the immediate programmed consequences (point). In addition, discrepant rule following is maintained in Phase 3 of the study by Albuquerque et al. (in press), possibly because the behavior detected prior to the presentation of the discrepant rule is maintained, independently of its immediate consequences. One piece of evidence is that rule following is maintained in Phases 2 and 3 of this study, independently of its immediate programmed consequences (Albuquerque et al., in press).

Considering this analysis, in the present study, we attempt to perform a systematic replication of Experiment 2 of the study by Albuquerque et al. (2008); however, unlike this study and similar to the study by Albuquerque et al. (2014, Group IN), the present study is conducted to test the dependence of the behavior established by the correspondent rule on its immediate consequences, before the presentation of the discrepant rule. More specifically, in Phase 2 of the present study, we attempt to build a history that is identical to Phase 2 of the study by Albuquerque et al. (2008, Experiment 2 - prolonged CRF). In Phase 3 , unlike the previous study (Albuquerque et al., 2008, Experiment 2), we seek to change, without warning, the contingencies of reinforcement 
that were in place in Phase 2. In Phase 4, we seek to introduce the discrepant rule and keep unchanged the contingencies of reinforcement that were in place in Phase 3. Accordingly, if the dependence and independence of the behavior on its immediate consequences, before the presentation of the discrepant rule, are critical variables in the history of the listener that can be used to predict the maintenance, or not, of subsequent discrepant rule following, then it should be expected that discrepant rule following would be maintained if preceded by a history of independence and would not occur if preceded by a history of dependence of the behavior on its immediate consequences. Thus, in the present study, we attempt to experimentally evaluate these possibilities.

\section{Method}

\section{Participants}

Eight university students without prior experience in this type of research, from different majors (except Psychology) and enrolled in different semesters, participated in the experiment. They included two men and six women, aged between 18 and 23 years old.

\section{Ethical Procedures}

All participants were volunteers and signed a consent form that described in general terms that the aim of the study was to investigate learning processes that are common to all people and that, if the participant felt uncomfortable for any reason, then she/he could end her/ his participation in the study at any time and withdraw consent. The project was approved by the Ethics Committee (Protocol: No. 004/2011$\mathrm{CEP} / \mathrm{NMT}$ ).

\section{Equipment and Material}

A wooden table measuring $150 \times 78 \times 70 \mathrm{~cm}$ was used. Secured to the table, to divide it in half lengthwise, was a $150 \times 60 \mathrm{~cm}$ one-way mirror, set in a wood frame and located $13 \mathrm{~cm}$ above the table top. In the center of the frame, close to the table top, was a rectangular opening. Above and to the center of this opening, there was a counter operated by the experimenter, with the display side facing the participant. A 5-watt clear light bulb, visible to the participant, was installed on the frame. A paper label with the sentence "You got a point" was placed on the frame above the lamp. A 15-watt fluorescent light bulb was installed on the top edge and the center of the frame. The table was placed at the center of a room with air-conditioning.

The sample and comparison stimuli were wood pieces (logical blocks, FUNBEC brand) varying in three dimensions: shape (square, circle, rectangle, and triangle), color (blue, red, and yellow) and thickness (thick and thin). These wood pieces formed 40 different stimulus arrangements, each composed of a sample stimulus and three comparison stimuli. Each comparison stimulus had only one dimension - color (C), thickness (T), or shape (S) - in common with the sample stimulus and differed from the others. The stimulus arrangements, previously prepared, were placed on top of the table, next to the experimenter, in the order in which they would be presented in each trial. The stimuli were presented to the participant through the opening at the base of the frame dividing the table, on a T-shaped wooden tray. At the end of the handle of this tray, four wooden slats formed a square, in which the model stimulus was placed. On the rectangular base, divided into three squares by wooden slats, were the three comparison stimuli. The responses of pointing to the comparison stimuli were recorded by the experimenter in a previously prepared form and were also recorded by a camcorder for further analysis. The reinforcers used were points, recorded in the counter. Each point was worth Brazilian Real (BRL) 0.05 (five cents). The rules were recorded, and the recording was presented to the participant via headphones connected to the audio recorder.

\section{Procedure}

During the experimental session, the participant and the experimenter sat at the table, facing each other, separated by the table divider. The light bulb on the top edge of the frame was on 
continuously, directed toward the participant, to ensure that the participant's side had lighting of greater intensity, ensuring that only the participant's actions, in addition to the stimulus arrangement, could be seen through the mirror. The four phases of the experiment (described below) were conducted in a single experimental session that lasted $90 \mathrm{~min}$. At the beginning of Phases 1,2 , and 4 , the experimenter showed a particular rule to the participant and then presented the stimulus arrangements. In Phase 3, there were no rules, only the stimulus arrangements. The phases lasted $20 \mathrm{~min}$ on average. The interval between phases was approximately $3 \mathrm{~min}$.

On each trial, the experimenter showed one of the 40 stimulus arrangements. In the presence of these stimuli, the participant was supposed to point to each of the three comparison stimuli in a given sequence. If the sequence of responses were in accordance with the programmed contingencies of reinforcement (the correct sequence), then a point was added in the counter, the clear bulb went on and off, and the tray with the stimulus arrangement was taken away. If the sequence of responses was incorrect, then the clear bulb was not lit, and the tray with the stimulus arrangement was taken away; however, a point was not added in the counter. There was a variable interval of approximately $5 \mathrm{~s}$ between one trial and the next. The points were recorded cumulatively in the counter.

\section{Preliminary Guidelines}

At the beginning of the experiment, when the participant and the experimenter entered the room, the tray with the stimulus arrangement was on the table and therefore visible to the participant. The experimenter asked the participant to sit in the chair and put the headphones on. On the other side of the table, the research assistant turned the recorder on. Through the headphones, the participant heard the following guidelines:

This object, on the top, is a sample. These three objects, below, are for you to compare with the sample. We'll call these three objects, down here, comparison objects. Note that each of these three comparison objects has a single property in common with the sample. Look. This one only has the thickness in common with the model. This one only has the color in common with the sample. This one only has the shape in common with the sample. During the study, you can earn points that will be exchanged for cash. When you earn points, the points will always appear here in this counter. Here's how the points appear in the counter [the assistant, who was on the other side of the table, triggered the counter and lit the light bulb five times]. When you don't win points, no points will be added to the counter. Do you understand? The experimenter, next to the participant, always pointed with her/his finger to each of the stimuli to which the recording referred. This procedure occurred only at the beginning of the experiment.

\section{Rules}

Next, the experimenter, separated from the participant by the frame with a one-way mirror, depending on the experimental phase, handed to the participant, through the opening at the base of the frame, a sheet of paper containing one of the following printed rules:

\section{Minimal Rule:}

Point with your finger, in sequence, to each of the three comparison objects.

\section{Correspondent Rule:}

When I show you these objects, you must do the following: first, point with your finger to the comparison object that has the same thickness (T) as the sample object. Then, point to the comparison object that has the same shape (S) as the sample object. Then, point to the comparison object that has the same color (C) as the sample object. Therefore, you should first point to the same thickness, then to the same shape, and then to the same color of the sample object. Do you understand? Repeat to me what you should do. By doing so, you can earn points that will be shown in the counter in front of you. Each point you earn will be exchanged for BRL 0.05 (five cents) but only at the end of the study. 


\section{Discrepant Rule:}

When I show you these objects, you must do the following: first, point with your finger to the comparison object that has the same shape (S) as the sample object. Then, point to the comparison object that has the same color (C) as the sample object. Then, point to the comparison object that has the same thickness (T) as the sample object. Therefore, you must point first to the same shape, then to the same color, and then to the same thickness. Do you understand? Repeat to me what you should do. By doing so, you can earn points that will be shown in the counter in front of you, and each point you earn will be exchanged for BRL 0.05 (five cents) but only at the end of the study".

\section{Rule Presentation}

Immediately after handing the sheet of paper containing the printed rule to the participant, the experimenter turned on the audio player device, and the participant listened to the recording of the experimenter voice, reading the rule concerning the session to be initiated. In the recording, the experimenter asked the participant to sometimes follow the reading and sometimes silently read alone. After the last reading, the recording asked the participant to return the rule sheet. Soon after the participant returned the rule sheet, the research assistant removed the tray and then presented the tray again with a new stimulus arrangement, and the experimenter said: "Start pointing".

\section{Experimental Design}

The experiment consisted of four phases. Phase 1 began with the introduction of the minimal rule; Phase 2 with the correspondent rule; Phase 3 with the unwarned change in the programmed contingencies; and Phase 4 with the discrepant rule.

Phase 1 consisted of 10 baseline trials to which the effects of introducing the correspondent rule in Phase 2 were compared. During Phase 1, no sequence of responses was reinforced or described by a rule. During Phases 2, 3 , and 4 , the correct sequences were reinforced, with points exchangeable for cash, in a continuous reinforcement schedule.

In Phase 2, the only sequence that produced points (correct) was TSC, specified by the correspondent rule. Phase 2 was terminated after 320 points were earned. In Phase 3, the TSC sequence (correct in Phase 2) stopped producing points, and the CTS sequence became the only sequence (correct) that produced points. Phase 3 was terminated after 80 trials. In Phase 4, the CTS sequence (correct in Phase 3 ) was still the only sequence (correct) that produced points. Therefore, the incorrect SCT sequence, specified by the discrepant rule, did not produce points. Phase 4 was also terminated after 80 trials.

\section{Comparison of Records and Completion of Student Participation in the Experiment}

At the end of Phase 4, an independent observer compared the recording made by the experimenter in the worksheet with the camcorder recording. If there was a $100 \%$ match between the records, the data were considered for analysis. Otherwise, they were discarded. No data were discarded in this study. Student participation in the experiment was completed after reaching the termination criterion of Phase 4.

\section{Data Analysis}

First, the Phase 3 history effects on the maintenance of discrepant rule following in Phase 4 were analyzed (the transition from Phase 3 to Phase 4) because doing so is the objective of the present study. However, assumptions about the Phase 2 history effects on the behavior in Phase 3 (transition from Phase 2 to Phase 3) were also made.

\section{Results}

The data are shown for each phase, and comparisons are made between phases. Table 1 shows the percentages of response sequences expressed during the four phases by the eight participants. In Phase 1, the participants vary their performances, showing different sequences. 
Table 1

Percentages of Sequences Expressed by the Participants (P) during the Phases $1,2,3$, and 4 .

\begin{tabular}{|c|c|c|c|c|c|c|}
\hline Participants & & Rest & nse sequ & nces & & \\
\hline Phase 1 & TSC & TCS & $\mathrm{SCT}$ & STC & CTS & CST \\
\hline P11 & 0 & 80 & 10 & 0 & 0 & 10 \\
\hline P12 & 30 & 10 & 20 & 30 & 10 & 0 \\
\hline P13 & 0 & 20 & 10 & 30 & 30 & 10 \\
\hline P14 & 10 & 30 & 10 & 30 & 20 & 0 \\
\hline P15 & 20 & 10 & 0 & 40 & 20 & 10 \\
\hline P16 & 0 & 30 & 20 & 20 & 20 & 10 \\
\hline P17 & 0 & 0 & 40 & 40 & 0 & 20 \\
\hline P18 & 20 & 0 & 20 & 10 & 20 & 30 \\
\hline Phase 2 & TSC & TCS & $\mathrm{SCT}$ & STC & CTS & CST \\
\hline P11 & $100 *$ & 0 & 0 & 0 & 0 & 0 \\
\hline P12 & $100 *$ & 0 & 0 & 0 & 0 & 0 \\
\hline P13 & $100 *$ & 0 & 0 & 0 & 0 & 0 \\
\hline P14 & $100 *$ & 0 & 0 & 0 & 0 & 0 \\
\hline P15 & $100 *$ & 0 & 0 & 0 & 0 & 0 \\
\hline P16 & $100 *$ & 0 & 0 & 0 & 0 & 0 \\
\hline P17 & $100^{*}$ & 0 & 0 & 0 & 0 & 0 \\
\hline P18 & $100^{*}$ & 0 & 0 & 0 & 0 & 0 \\
\hline Phase 3 & TSC & TCS & SCT & STC & CTS & CST \\
\hline P11 & 100 & 0 & 0 & 0 & 0 & 0 \\
\hline P12 & 98 & 1 & 0 & 1 & 0 & 0 \\
\hline P13 & 100 & 0 & 0 & 0 & 0 & 0 \\
\hline P14 & 10 & 1 & 1 & 1 & $87 *$ & 0 \\
\hline P15 & 99 & 1 & 0 & 0 & 0 & 0 \\
\hline P16 & 9 & 5 & 2 & 0 & $65^{*}$ & 19 \\
\hline P17 & 100 & 0 & 0 & 0 & 0 & 0 \\
\hline P18 & 91 & 3 & 1 & 0 & 0 & 5 \\
\hline Phase 4 & TSC & TCS & $\mathrm{SCT}$ & STC & CTS & CST \\
\hline P11 & 0 & 0 & $100 * *$ & 0 & 0 & 0 \\
\hline P12 & 0 & 0 & $99 * *$ & 0 & 0 & 1 \\
\hline P13 & 0 & 0 & $100 * *$ & 0 & 0 & 0 \\
\hline P14 & 0 & 0 & $3 * *$ & 1 & $96^{*}$ & 0 \\
\hline P15 & 1 & 0 & $99 * *$ & 0 & 0 & 0 \\
\hline P16 & 0 & 0 & $3 * *$ & 0 & $97 *$ & 0 \\
\hline P17 & 4 & 1 & $24 * *$ & 1 & $29 *$ & 41 \\
\hline P18 & 1 & 0 & $31^{* *}$ & & $3 *$ & 65 \\
\hline
\end{tabular}

Note. $\mathrm{C}=$ response to the color dimension; $\mathrm{T}=$ response to the thickness dimension; $\mathrm{S}=$ response to the shape dimension. ${ }^{*}$ Indicates reinforced sequence. ${ }^{* *}$ Indicates sequence specified by the discrepant rule. Sessions 1, 2, 3, and 4 were initiated by: minimal rule, correspondent rule, unwarned change in the programmed contingencies, and discrepant rule, respectively. 
In Phase 2, when the correspondent rule is introduced, all eight participants follow this rule in $100 \%$ of the trials. In Phase 3, when the programmed contingencies of reinforcement are changed, six of the eight participants (P11, P12, P13, P15, P17, and P18) continue emitting the TSC sequence, previously specified by the correspondent rule; that is, they continue rule following, even though this behavior no longer produces the programmed reinforcement. In contrast, P14 and P16 cease to follow the rule and begin to respond correctly by emitting the CTS sequence.

In Phase 4, when the discrepant rule is introduced and the programmed contingencies of reinforcement are kept unchanged, of the six participants (P11, P12, P13, P15, P17, and $\mathrm{P} 18)$ who display a behavior that is independent of the immediate consequences programmed in Phase 3, four (P11, P12, P13, and P15) follow the discrepant rule and thereby also present a behavior that is independent of the immediate consequences programmed in Phase 4. Additionally, of the two participants (P16 and P14) who display a behavior that is dependent on the immediate consequences programmed in Phase 3, all abandon discrepant rule following and thereby also present a behavior that is dependent on the immediate consequences programmed in Phase 4.

P17, who continues rule following in Phase 3 , stops following the discrepant rule in trial 59 of Phase 4, emitted the incorrect CST sequence, and proceeds to answer correctly at the end of Phase 4. P18 also continues rule following in Phase 3 and stops following the discrepant rule in Phase 4. Then, this participant proceeds to present the incorrect CST sequence. Thus, P18 also displays a behavior that is independent of the contingencies of reinforcement programmed in Phases 3 and 4.

\section{Discussion}

In the present study, we attempt to test the proposition that suggests that the dependence and independence of behavior on its immediate consequences, before the presentation of the dis- crepant rule, are critical variables, constituents of the listener's history, which can be used to predict the maintenance, or not, of subsequent discrepant rule following (Albuquerque \& Paracampo, 2017 b; Albuquerque et al., in press). The results of six of the eight participants (75\%) of this study replicate the results from previous studies (Albuquerque \& Paracampo, 2017b; Albuquerque et al., 2013; Albuquerque et al., 2014; Pinto, Paracampo, \& Albuquerque, 2006) and support this proposition. As this proposition suggests, discrepant rule following is likely to be maintained when, before the introduction of this rule, the participant displays a behavior that is independent of its immediate consequences (P11, P12, P13 and P15); furthermore, discrepant rule following is likely to fail to occur when, before the introduction of this rule, the participant displays a behavior that is dependent on its immediate consequences (P16 and P14). Therefore, the differences between following and not following the discrepant rule partly depend on the differences between the listeners' histories (Albuquerque \& Paracampo, 2017b; Albuquerque \& Paracampo, in press; Albuquerque et al., in press; Albuquerque et al., 2014).

However, it is difficult to explain why the behaviors of Participants P11, P12, P13, and $\mathrm{P} 15$ are maintained independently of their immediate consequences and why the behaviors of Participants P14 and P16 are maintained dependent on such consequences in Phase 3. It is not clear why these differences occur, but some suggestions can be made for future studies. The individual differences found in this study may be partly due to possible differences in the participants' pre-experimental rule-following histories because these differences are also found in previous studies (Albuquerque et al., 2013, Albuquerque et al., 2014; Pinto et al., 2006). This proposition is also based on the experimental results of some studies that have investigated the effects of pre-experimental histories (inferred from the listener's responses to the questionnaire regarding inflexibility developed by Rehfisch, 1958) on rule following (Albuquerque \& Paracampo, 2017b; Paracampo, Souza, \& Albuquerque, 2014; Pinto et al., 2006; 
Wulfert, Greenway, Farkas, Hayes, \& Douguer, 1994). For example, Pinto et al. (2006) expose eight university students (four flexible and four inflexible) to a procedure that differs from that used in Group IN of the study by Albuquerque et al. (2014), mainly because the eight participants are pre-selected based on their responses to the questionnaire about inflexibility. The five participants (four inflexible and one flexible) who continue rule following in Phase 3 (i.e., who maintain a behavior that is independent of its immediate consequences), follow the discrepant rule in Phase 4, and the three participants (all flexible) who cease rule following in Phase 3 and begin displaying a behavior that is dependent on its immediate consequences stop discrepant rule following in Phase 4. These results, combined with the results of the present study, indicate that pre-experimental histories (inferred from the listener's responses to the questionnaire on inflexibility) can interfere with the behavior of rule following and not following.

However, the results by Pinto et al. (2006) do not indicate which pre-experimental history interferes in behavior; that is, they do not indicate whether the listener's history is of control (a) by differential immediate consequences, (b) by differential justifications, or (c) by the interaction between justifications and differential immediate consequences, for both rule following and not following. In addition, there is experimental evidence that indicates that the possible effects of pre-experimental histories in determining individual differences partly depend on the current environmental variables to which the listeners are exposed (Paracampo et al., 2014). According to this proposition, the current environmental variables are those that favor, or not, the possible effects of pre-experimental histories in determining individual differences (Albuquerque \& Paracampo, 2017b; Albuquerque \& Paracampo, in press; Paracampo et al., 2014). In this study, there is evidence to support this proposition.

For example, the results of the present study, which show that there are differences between the participants' performances in Phase 1, 3, and 4 and that such differences do not occur in Phase
2, indicate that, unlike Phase 2, in Phases 1, 3, and 4 , there are variables that can favor the effects of pre-experimental histories in determining individual differences. In Phase 1, all participants follow the minimal rule; that is, as specified by this rule, all participants display the behavior of pointing with their finger (and not another) to each of the three comparison stimuli (and not to other stimuli). They point in different sequences because the minimal rule does not specify a sequence. Evidence thereof is that this variability is eliminated in Phase 2, when the correspondent rule, which specifies the sequence to be emitted, is introduced and all participants begin to present the specified sequence. However, specifying the behavior to be emitted, by itself, is not sufficient to explain why no differences are found among the performances of the participants in Phase 2, given that, in Phase 4, the introduced discrepant rule also specifies this behavior and such differences are observed. A variable that interferes in the occurrence, or not, of differences among the performances of the participants is the Type 1 justification (statements about the eventual consequences of following or not following rules): "By doing so, you can earn points that will be shown in the counter in front of you". That is, the results of this study show that the differences between the performances of the participants are more likely to occur when this justification does not correspond (Phases 3 and 4) than when they correspond (Phase 2) to the immediate consequences produced by the behavior specified by the rule.

According to this analysis, in addition to the pre-experimental histories, current environmental variables may have also determined the performances of the participants. In the case of P14 and P16, the contact of rule following with the discrepancy between the Type 1 justification (the promise of earning points) and the immediate consequences (not earning points) produced by this behavior in Phases 3 and 4 possibly contributes to these two participants' (P16 and P14) ceasing rule following in these sessions (Galizio, 1979). Discrimination of this discrepancy may have been facilitated by the difference between the extended history 
of continuous reinforcement of rule following in Phase 2 and the extinction produced by this behavior in Phase 3 (Albuquerque et al., 2008; Cerutti, 1989; Newman et al., 1995). The fact that not following the rule is reinforced in a continuous reinforcement schedule may have also favored the abandonment of rule following (Paracampo \& Albuquerque, 2004).

However, it is difficult to explain why, even when exposed to these variables that favor the abandonment of rule following, Participants P11, P12, P13, and P15 continue rule following in Phase 3. To attempt to clarify this question, it is necessary to also consider the effects on rule following of the Type 2 justification (statements about the eventual approval or disapproval of the rule following or not following): "When I show you these objects, you must do the following: ...". This consideration is necessary because there is experimental evidence that shows that examples of Type 2 justifications that indicate that the speaker approves or requires that the rule is followed, such as that which is presented to the participants in this study, are more likely to maintain the behavior specified by discrepant rules than Type 2 justifications that do not clearly indicate that the speaker approves or requires that the rule be followed.

For example, there is experimental evidence (Albuquerque et al., 2011) that shows that the subsequent behavior specified by the discrepant rule has a higher probability of being installed and maintained when the discrepant rule contains the Type 2 justification (i.e., "When I show you these objects, I want you to do the following: ..."; for the authors, examples of Type 2 justifications such as this can indicate that rule following is being monitored, that the speaker cares about rule following, and that not following the rule clearly implies disobeying the speaker), than when this rule contains the Type 2 justification (i.e., "When I show you these objects, do whatever you think is best for you. If you want to, you can do the following: ... "; for the authors, examples of Type 2 justification such as this can indicate that rule following is not being monitored, that the listener is not required to follow the rule, and, therefore, that not following the rule will not be punished by the speaker). Such results suggest that the effects of justifications should be considered in the explanation of maintaining behavior specified by rules (also, see Albuquerque \& Paracampo, in press).

However, according to Albuquerque et al. (2014), the effects of justifications, instead of being considered effects of verbal antecedent stimuli (i.e., of rule's constituent stimuli), are considered as though they are effects of immediate consequences (i.e., of contingencies of reinforcement) or, more specifically, as though they are effects of verbal contingencies (Skinner, 1969), socially mediated consequences (Hayes et al., 1986; Zettle \& Hayes, 1982), instructional consequences (Cerutti, 1989), cultural consequences (Matos, 2001), contingencies that act directly and indirectly (Malott, 1989), proximate contingency and ultimate contingency (Baum, 1994/1999), and higher-order verbal and social contingencies (Catania, 1998). The problem of using such terms is that they do not help clarify the distinction between what is control by rule's constituent stimuli and what is control by stimuli as part of the contingencies of reinforcement and, therefore, do not contribute to distinguishing what is control by rules and what is control by contingencies.

According to Albuquerque et al. (2014), the speaker can indicate to the listener that she/he approves or disapproves of answering according to a rule by justifications or by immediate consequences. The difference is that the stimuli (such as criticism, praise, admiration, rejection, correct or incorrect behavior) are presented before the occurrence of the behavior in the first case and immediately after the occurrence of the behavior in the second case (also, see Albuquerque \& Paracampo, in press).

According to this proposition, the results of this study, combined with the results of similar studies (Albuquerque et al., 2011; Albuquerque et al., in press; Albuquerque et al., 2014), suggest that, in Phase 2 of this study, Participants $\mathrm{P} 11, \mathrm{P} 12, \mathrm{P} 13$, and P15 follow the rule, possibly more under the control of the Type 2 justification (statements about the eventual approval or disapproval for following or not following the rule) 
than the correspondence between the Type 1 justification (statements about the eventual consequences of following or not following rules) and the immediate consequences. Evidence thereof is that the behavior specified by the rule continues to be maintained in Phase 3, even when this correspondence ceases to exist (i.e., when it stops producing the immediate consequences (the points) promised in the Type 1 justification). Thus, the history of control by Type 2 justification ("When I show you these objects, you must do the following:") of Phase 2 may have contributed to maintaining rule following in Phase 3 , insofar as such justification may have indicated to do what the rule specified is correct, what should be done, and, therefore, what can produce approval or avoid any future criticism.

On the other hand, it is possible that Participants P16 and P14 follow the rule in Phase 2 more under the control of the immediate programmed consequences for rule following than Types 1 and 2 justifications. Evidence thereof is that, in Phase 3, when rule following ceases to produce such immediate consequences, $\mathrm{P} 14$ and P16 cease to follow the rule and proceed to present a behavior that is dependent on its immediate consequences; that is, the history of control by immediate consequences programmed for Phase 2 rule following may have contributed to preventing the maintenance of rule following that does not produce such immediate consequences and maintaining a behavior that is dependent on its immediate consequences in Phase 3.

The results of Phase 4 show additional empirical evidence that the behavior presented by $\mathrm{P} 14$ and P16 is maintained dependent on immediate consequences and independent of justifications for rule following and that the behavior shown by $\mathrm{P} 11, \mathrm{P} 12, \mathrm{P} 13$, and $\mathrm{P} 15$ is maintained independent of such consequences and dependent on Type 2 justifications for rule following. This functional distinction between the behaviors of these participants is the distinction between behavior controlled by rules (P11, P12, $\mathrm{P} 13$ and P15) and behavior controlled by contingencies of reinforcement (P16 and P14; Albuquerque \& Paracampo, in press; Albuquerque et al., in press).
Regarding Participants P17 and P18, it can be said that P17 behaves similarly to P11, P12, P13, and P15 until trial 59 of Phase 4 and that, in general, the performance of $\mathrm{P} 18$ is also similar to that exhibited by $\mathrm{P} 11, \mathrm{P} 12, \mathrm{P} 13$, and $\mathrm{P} 15$, given that all five participants display a behavior that is independent of its immediate consequences in Phases 3 and 4. However, the data showing that P17 and P18 follow the rule in Phases 2 and 3 and cease rule following in Phase 4 suggest that these two participants respond under the control of other variables. P17 and P18 follow the rule in Phase 3, possibly not only due to the historical control by Type 2 justification but also due to the historical control by interaction between the Type 1 justification and the immediate consequences of rule following. Thus, the time of exposure to the discrepancy between these variables (the Type 1 justification and the immediate consequences) in Phases 3 and 4 may have contributed to ceasing discrepant rule following in Phase 4. Evidence thereof is that both participants earn points after they stop rule following. What is not clear is why P18, rather than continue expressing the CTS sequence (correct), expresses the CST sequence, which is formally similar to the correct sequence. This type of error has been found in other studies.

In summary, the results of six of the eight participants of this study support the proposition that maintaining discrepant rule following partly depends on two critical characteristics of the listener's history. One of these characteristics is whether the behavior displayed by the listener, before her/his contact with the discrepant rule, is maintained dependent on its immediate consequences. The other characteristic is whether this behavior is maintained independent of such consequences. Based on these historical characteristics, the likelihood that discrepant rule following will be maintained or not can be predicted. This behavior displayed by the listener before contact with the discrepant rule, in turn, tends to be maintained dependent on its immediate consequences, when its maintenance is favored by historical control by immediate consequences for following (such as that built in Phase 2) and for not following a rule (such as 
that built in Phase 3), and tends to be maintained independent of its immediate consequences, when its maintenance is favored by historical control by Type 2 justification (such as that built in Phase 2; Albuquerque \& Paracampo, 2017b; Albuquerque et al., in press). Future studies can perform a systematic replication of this experiment to test this assumption concerning the effects of this historical control by Type 2 justification. One of the advantages of systematic replication is that its results can be compared with the results of previous studies of the same related research program.

\section{References}

Albuquerque, L. C. (1991). Efeitos de regras no controle do comportamento humano [Abstract]. In Sociedade Brasileira de Psicologia (Ed.), Resumos de comunicações cientificas. XXI Reunião Anual de Psicologia (p. 162). Ribeirão Preto, SP: Sociedade Brasileira de Psicologia.

Albuquerque, L. C., de Souza, D. G., Matos, M. A., \& Paracampo, C. C. P. (2003). Análise dos efeitos de histórias experimentais sobre o seguimento subsequente de regras. Acta Comportamentalia, 11, 87-126.

Albuquerque, L. C., Mescouto, W. A., \& Paracampo, C. C. P. (2011). Controle por regras: Efeitos de perguntas, sugestões e ordens. Acta Comportamentalia, 19, 19-42.

Albuquerque, L. C., \& Paracampo, C. C. P. (2017a). Theory of control by justifications and immediate consequences. In J. C. Todorov (Ed.), Trends in Behavior Analysis: Vol. 2 (pp. 125-152). Brasília, DF: Technopolitik.

Albuquerque, L. C., \& Paracampo, C. C. P. (2017b). Control by stimuli constituent of rules and reinforcement contingencies. In J. C. Todorov (Ed.), Trends in Behavior Analysis: Vol. 2 (pp. 153191). Brasília, DF: Technopolitik.

Albuquerque, L. C., \& Paracampo, C. C. P. (in press). Selection of behavior by justifications constituent of rules. Trends in Psychology. Manuscript submitted for publication.

Albuquerque, L. C., Paracampo, C. C. P., \& Allan, S. (in press). Análise de variáveis que podem determinar as funções de regras e de contingências de reforço. Acta Comportamentalia. Manuscript submitted for publication.
Albuquerque, L. C., Paracampo, C. C. P., Matsuo, G. L., \& Mescouto, W. A. (2013). Variáveis combinadas, comportamento governado por regras e comportamento modelado por contingência. Acta Comportamentalia, 21, 285-304.

Albuquerque, L. C., Reis, A. A., \& Paracampo, C. C. P. (2006). Efeitos de uma história de reforço contínuo sobre o seguimento de regra. Acta Comportamentalia, 14, 47-75.

Albuquerque, L. C., Reis, A. A., \& Paracampo, C. C. P. (2008). Efeitos de histórias de reforço, curtas e prolongadas, sobre o seguimento de regras. Acta Comportamentalia, 16, 305-332.

Albuquerque, L. C., \& Silva, F. M. (2006). Efeitos da exposição a mudanças nas contingências sobre o seguir regras. Psicologia: Teoria e Pesquisa, $22,101-112$.

Albuquerque, L. C., Silva, L. S., \& Paracampo, C. C. P. (2014). Análise de variáveis que podem interferir no comportamento de seguir regras discrepantes. Acta Comportamentalia, 22, 51-71.

Baum, W. M. (1999). Compreender o behaviorismo: Ciência, comportamento e cultura. Porto Alegre, RS: Artmed (Original work published 1994)

Catania, A. C. (1998). Learning. Hillsdale, NJ: Prentice Hall.

Cerutti, D. T. (1989). Discrimination theory of rulegovernedbehavior. Journal of the Experimental Analysis of Behavior, 51, 259-276.

Galizio, M. (1979). Contingency-shaped and rulegoverned behavior: Instructional control of human loss avoidance. Journal of the Experimental Analysis of Behavior, 31, 53-70.

Hayes, S. C., Brownstein, A. J., Zettle, R. D., Rosenfarb, I., \& Korn, Z. (1986). Rule governed behavior and sensitivity to changing consequences of responding. Journal of the Experimental Analysis of Behavior, 45, 237-256.

Malott, R. M. (1989). Achievement of evasive goals. In S. C. Hayes (Ed.), Rule governed behavior: Cognition, contingencies, and instructional control (pp. 153-190). New York: Plenum.

Martinez, H., \& Tomayo, R. (2005). Interactions of contingencies, instructional accuracy, and instructional history in conditional discrimination. The Psychological Record, 55, 633-646.

Matos, M. A. (2001). Comportamento governado por regras. Revista Brasileira de Terapia Comportamental e Cognitiva, 2, 51-66. 
Matsuo, G. L., Albuquerque, L. C., \& Paracampo, C. C. P. (2014). Efeitos de justificativas relatadas em regras sobre o seguimento de regras. Acta Comportamentalia, 22, 273-293.

Newman, B., Buffington, D. M., \& Hemmes, N. S. (1995). The effects of schedules of reinforcement on instruction following. The Psychological Record, 45, 463-476.

Paracampo, C. C. P., \& Albuquerque, L. C. (2004). Análise do papel das consequências programadas no seguimento de regras. Interação em Psicologia, 8, 237-245.

Paracampo, C. C. P., Albuquerque, L. C., Mescouto, W. A., \& Farias, A. F. (2013). Efeitos de perguntas e de respostas às perguntas sobre o seguir regras. Psicologia: Teoria e Pesquisa, 29, 63-74.

Paracampo, C. C. P., Souza, L. M., \& Albuquerque, L. C. (2014). Variáveis que podem interferir no seguir regras de participantes flexíveis e inflexíveis. Psicologia: Reflexão e Crítica, 27, 124-133.

Perez, W. F., Reis, M. J. D., \& de Souza, D. G. (2010). Efeitos de história experimental com diferentes instruções e do controle por contingências sobre o seguimento de instruções. Acta Comportamentalia, 18, 55-85.

Pinto, A. R., Paracampo, C. C. P., \& Albuquerque, L. C. (2006). Análise do controle por regras em participantes classificados de flexíveis e de inflexíveis. Acta Comportamentalia, 14, 171-194.

Rehfisch, J. M. (1958). A Scale for Personality Rigidity. Journal of Consulting Psychology, 1, 11-15.

Schlinger, H., \& Blakely, E. (1987). Function-altering effects of contingency-specifying stimuli. The Behavior Analyst, 10, 41-45. doi:10.1007/ BF03392405
Shimoff, E., Catania, A. C., \& Matthews, B. A. (1981). Uninstructed human responding: Sensitivity of low-rate performance to schedule contingencies. Journal of the Experimental Analysis of Behavior, 36, 207-220. doi:10.1901/jeab.1981.36-207

Skinner, B. F. (1969). Contingencies of reinforcement: A theoretical analysis. New York: Appleton-Century-Crofts.

Skinner, B. F. (1974). About behaviorism. New York: Alfred A. Knopf.

Torgrud, L. J., \& Holborn, S. W. (1990). The effects of verbal performance descriptions on nonverbal operant responding. Journal of the Experimental Analysis of Behavior, 54, 273-291. doi:10.1901/ jeab.1990.54-273

Wulfert, E., Greenway, D. E., Farkas, P., Hayes, S. C., \& Dougher, M. J. (1994). Correlation between self-reported rigidity and rule-governed insensivity to operant contingencies. Journal of Applied Behavior Analysis, 27, 659-671. doi:10.1901/jaba.1994.27-659

Zettle, R. D., \& Hayes, S. C. (1982). Rule-governed behavior: A potential theoretical framework for cognitive-behavior therapy. In P. C. Kendall (Ed.), Advances in cognitive-behavioral research and therapy (pp. 73-118). New York: Academic Press. 